Article

\title{
Evaluating the Self-Sensing Ability of Cement Mortars Manufactured with Graphene Nanoplatelets, Virgin or Recycled Carbon Fibers through Piezoresistivity Tests
}

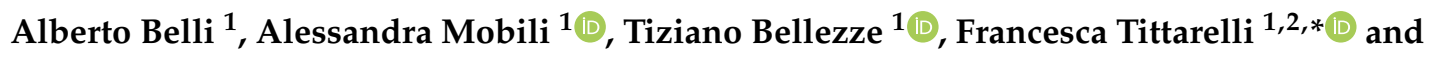 \\ Paulo Cachim ${ }^{3}$ (1) \\ 1 Department of Materials, Environmental Sciences and Urban Planning, Università Politecnica delle Marche, \\ via Brecce Bianche 12, INSTM Research Unit, Ancona 60131, Italy; alberto.belli@pm.univpm.it (A.B.); \\ a.mobili@univpm.it (A.M.); t.bellezze@univpm.it (T.B.) \\ 2 Institute of Atmospheric Sciences and Climate, National Research Council (ISAC-CNR), \\ Via Gobetti 101, Bologna 40129, Italy \\ 3 Department of Civil Engineering (DECIVIL), Universidade de Aveiro, RISCO Research Unit, \\ Aveiro 3810-193, Portugal; pcachim@ua.pt \\ * Correspondence: f.tittarelli@univpm.it; Tel.: +39-071-220-4732
}

Received: 28 September 2018; Accepted: 31 October 2018; Published: 2 November 2018

check for updates

\begin{abstract}
This paper presents the resistivity and piezoresistivity behavior of cement-based mortars manufactured with graphene nanoplatelet filler (GNP), virgin carbon fibers (VCF) and recycled carbon fibers (RCF). GNP was added at $4 \%$ of the cement weight, whereas two percentages of carbon fibers were chosen, namely $0.05 \%$ and $0.2 \%$ of the total volume. The combined effect of both filler and fibers was also investigated. Mortars were studied in terms of their mechanical properties (under flexure and compression) and electrical resistivity. Mortars with the lowest electrical resistivity values were also subjected to cyclic uniaxial compression to evaluate the variations in electrical resistivity as a function of strain. The results obtained show that mortars have piezoresistive behavior only if they are subjected to a prior drying process. In addition, dry specimens exhibit a high piezoresistivity only when loaded with 0.2 vol. $\%$ of VCF and $0.4 \mathrm{wt} . \%$ of GNP plus $0.2 \mathrm{vol} . \% \mathrm{RCF}$, with a quite reversible relation between their fractional change in resistivity (FCR) and compressive strain.
\end{abstract}

Keywords: cement; mortar; carbon fiber; filler; graphene; self-sensing; piezoresistivity; recycling; mechanical properties

\section{Introduction}

Over the last few decades, the development of novel multifunctional materials for both structural and non-structural applications has been particularly interesting. In particular, recent studies report the use of highly porous aggregates [1-3] or nano-photocatalytic materials [4-6] for indoor air quality improvement, smart compounds containing phase change materials $[7,8]$ for enhancing the thermo-energy efficiency and conductive additions for developing self-sensing materials [9-11].

Self-sensing is the ability of a structural material to sense its own condition, including strain, stress, damage and temperature [12]. This property is important for structural vibration control, load monitoring and structural health monitoring (SHM) for increasing the safety, durability and performance of the final material [13]. This aims to introduce non-destructive systems that are able to investigate the health of concrete through the detection of parameters such as $\mathrm{pH}$, humidity and the corrosion rate of the reinforcements or through sensors for the detection of cracks and damages. 
Strain gauges are a common tool used in non-destructive systems. When applied to the surface of the analyzed material, they allow an accurate measurement of its piezoresistivity characteristics/properties. Piezoresistivity is a physical characteristic of electrically-conductive materials, which leads to a variation in the electrical resistivity of the material subjected to strain [14]. In the presence of an elastic deformation, during the unloading phase, the material returns to its original conditions, with a perfectly repeatable effect.

In recent years, many authors have tried to increase the self-sensitivity of concrete to deterioration by using different types of additions (mainly carbon-based). It is well known that concrete has a low electrical conductivity [15]. The addition of conductive materials increases the conductivity of concrete through different phenomena, such as contacting conduction and the tunneling effect [16]. The former occurs at the direct contact of additions, while the latter is associated with the transmission of electrons between the disconnected, but close-enough additions. These materials create a conductive network that is modified when the material is subjected to stresses; thus, when the distance between particles decreases.

Materials such as carbon fibers have been reported to provide electrically conductive cement-based composites [12]. In particular, short carbon fibers have been shown to be the most effective additions for imparting a strain-sensing ability [14,17]. To date, carbon fibers have been used in several fields such as aerospace, automobile and sporting goods due to their high strength, high modulus, low density and reasonable cost, while their cost has only recently been decreasing, meaning that their applications have even broadened to the construction industry [18].

On the other hand, ordered mesoporous carbon (OMC) is used in energy storage for battery or supercapacitor electrodes, in chemical separations as membranes or absorbents and in electrodes in solar cells $[19,20]$.

Currently, some of the most innovative materials studied in construction application are graphene and its derivatives. Graphene is characterized by high mechanical resistance, as well as high thermal and electrical conductivities [21]. Graphene and its derivatives are widely used in polymer matrix composites in the field of electronics, aerospace, automotive and green energy, and they can also find applications in packaging, while few studies report their use in energy storage and electromagnetic interference shielding [22]. Over the last few decades, graphene's electrical properties have made it an interesting material for increasing the electrical conductivity of cement-based materials [23] and developing their piezoresistive behavior. Graphene nanoplatelets (GNP) are a relative low-cost filler consisting of graphene stacks, which exhibit a 2D sheet-like structure with a thickness around $10 \mathrm{~nm}$, which allows it to exhibit the extraordinary mechanical and electrical properties of graphene [24].

In the literature, there are only a few studies that have been performed on piezoresistive cements with GNP addition. Le et al. [23] reported that GNP filler makes the cementitious mortar in which it is added electrically conductive, and that when exceeding the percolation value (the limit beyond which the additions touch each other), the electrical conductivity is not influenced by the moisture content. In [25], Du and Pang found that GNP in a quantity higher than the percolation value permits mortars with piezoresistive properties to be obtained with a reversible trend under tensile load. Liu and coworkers [26] explained that GNP should be preferred to graphene oxide nanoplatelets (GONP) for producing electrical conductive mortars; moreover, GNP added in a quantity of $6.4 \%$ by cement weight showed stable electrical resistance and immediate and accurate reaction to compressive stress, whereas higher $(12.8 \%)$ or lower $(3.2 \%)$ contents gave unstable piezoresistance; however, at $6.4 \%$ content, the workability decreases considerably, and the mortar required extra water and superplasticizer.

It is reported that the use of both conductive fillers and fibers could be beneficial because they may enhance the electrical connectivity of the material, thereby resulting in a synergistic effect [17]. However, the combination of GNP and carbon fibers has not been studied yet. Therefore, in this work, the mechanical and electrical behavior of cement-based mortars loaded with GNP, virgin carbon fibers 
(VCF) and recycled carbon fibers (RCF) alone and together was compared, and their piezoresistive behavior was investigated under compression.

\section{Materials and Methods}

\subsection{Preparation of Mortars}

To manufacture conductive mortars, limestone cement CEM II B-LL 32.5N and silica sand (diameter $<1 \mathrm{~mm}$ ) were used.

As a conductive commercial filler, GNP, the commercial name of which is Pentagraf, was used. GNP was supplied by Pentachem S.r.l.

As conductive short fibers, virgin carbon fibers (VCF) and recycled carbon fibers (RCF) were used. VCFs were supplied by STW GmbH. RCFs were supplied by Apply Carbon S.A., and they are a mixture of all origins of carbon and graphite ex-PAN (polyacrylonitrile) fibers, obtained from spools of pure carbon fibers, cut for the widest range of short-fiber applications.

The morphology of GNP, VCF and RCF, investigated by scanning electron microscopy, is reported in Figure 1.

The properties of GNP, VCF and RCF reported in Table 1 have been taken from the technical data sheets given by suppliers.

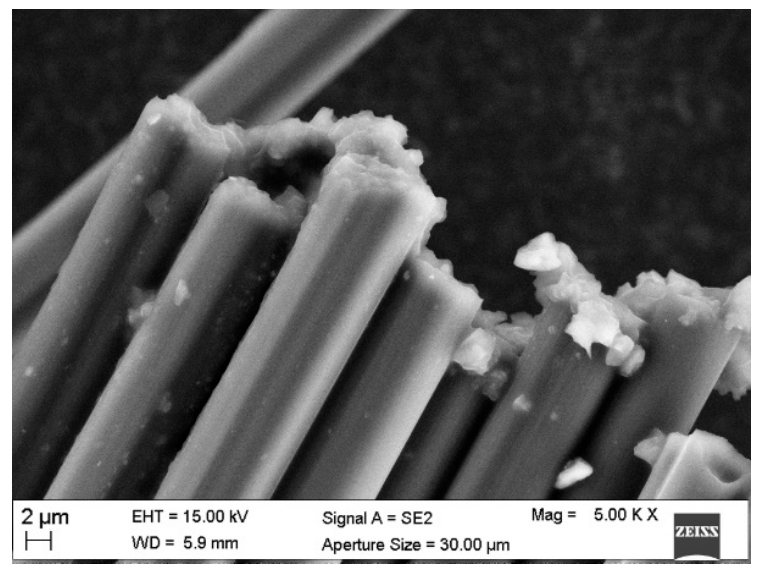

(a)

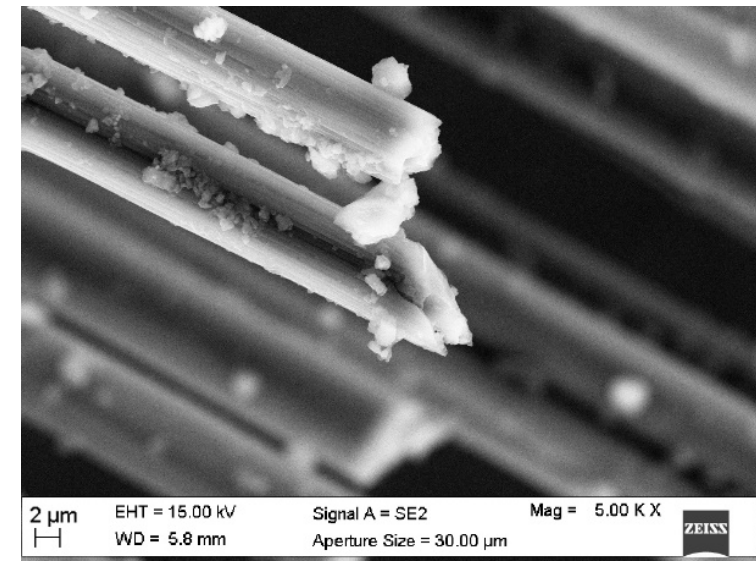

(b)

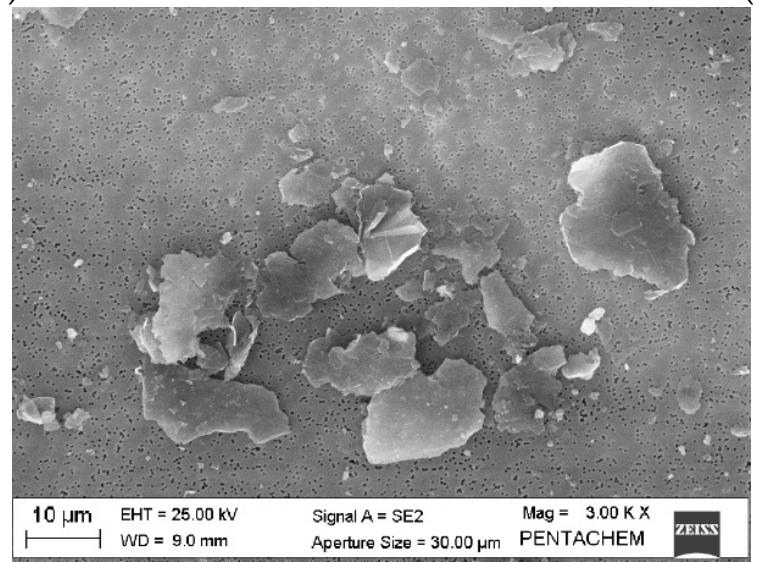

(c)

Figure 1. SEM images of (a) virgin carbon fibers (VCF), (b) recycled carbon fibers (RCF) and (c) graphene nanoplatelets (GNP). 
Table 1. Technical data of graphene nanoplatelets (GNP), virgin carbon fibers (VCF) and recycled carbon fibers (RCF).

\begin{tabular}{cccc}
\hline Properties & GNP & VCF & RCF \\
\hline Carbon content $(\%)$ & $>99.5$ & $>99.5$ & $94(>92)$ \\
Density $\left(\mathrm{g} / \mathrm{cm}^{3}\right)$ & 2.00 & 1.78 & 1.85 \\
Bulk density $\left(\mathrm{g} / \mathrm{cm}^{3}\right)$ & $0.03-0.10$ & - & - \\
Length $(\mathrm{mm})$ & - & 6.0 & 6.0 \\
Thickness $(\mu \mathrm{m})$ & $0.006-0.008$ & 7 & 7 \\
Tensile strength $(\mathrm{GPa})$ & - & 4 & 3.5 \\
Modulus $(\mathrm{GPa})$ & - & $230-250$ & 230 \\
Color & Black & Black & Black \\
Surface coating & - & Epoxy & Glycerol \\
\hline
\end{tabular}

GNP was added to mortars at $4 \%$ by cement weight (equal to $1 \%$ by the total volume of mortar), which is an amount similar to that used in a recent publication [23]. On the other hand, two dosages of fibers were chosen: the former equal to $0.05 \%$ by the total volume of mortar, which is similar to that used in premixed mortars, and the latter equal to $0.2 \%$ by the total volume of mortar, which is a percentage similar to that suggested by [27]. Fillers and fibers were added to mortars both alone and together to evaluate a possible synergistic effect of the two materials.

Mortars were manufactured with a sand/cement ratio equal to 3 and a water/cement ratio equal to 0.5 by weight. For comparison, a reference mixture (REF) without fillers and fibers addition was also manufactured.

The development of conductive behavior is feasible only if fillers and fibers are dispersed homogeneously in the compound. For this reason, in order to guarantee a uniform distribution of the conductive particles and eliminate the segregation, the dispersion of GNP was facilitated by mixing the filler in a solution composed of the total amount of water and a polycarboxylate ether agent (Melflux 4930F, Basf S.E.) as the superplasticizer (SP). At first, the solution was manually stirred and then subjected to sonication for $30 \mathrm{~min}$ in an ultrasonic bath.

The workability was maintained at a constant with a slump value lower than $210 \mathrm{~mm}$ to obtain plastic mortars according to UNI EN 1015-6:2007.

Mortars were cured at $\mathrm{RH}=90 \pm 5 \%$ and $\mathrm{T}=20 \pm 1{ }^{\circ} \mathrm{C}$ for the first week and then at $\mathrm{RH}=65 \pm 5 \%$ and $\mathrm{T}=20 \pm 1{ }^{\circ} \mathrm{C}$ in a climatic chamber until testing.

In Table 2, the composition and the relative slump flow values of all the studied mixtures are reported.

Table 2. Mix design (g/L) and workability (mm) of mortars.

\begin{tabular}{ccccccccc}
\hline Mixture & $\begin{array}{c}\text { Cement } \\
(\mathrm{g} / \mathrm{L})\end{array}$ & $\begin{array}{c}\text { Water } \\
(\mathrm{g} / \mathrm{L})\end{array}$ & $\begin{array}{c}\text { Sand } \\
(\mathrm{g} / \mathrm{L})\end{array}$ & $\begin{array}{c}\text { SP } \\
(\mathrm{g} / \mathrm{L})\end{array}$ & $\begin{array}{c}\text { GNP } \\
(\mathrm{g} / \mathrm{L})\end{array}$ & $\begin{array}{c}\text { VCF } \\
(\mathrm{g} / \mathrm{L})\end{array}$ & $\begin{array}{c}\text { RCF } \\
(\mathrm{g} / \mathrm{L})\end{array}$ & $\begin{array}{c}\text { Slump } \\
(\mathbf{m m})\end{array}$ \\
\hline REF & 512 & 256 & 1535 & - & - & - & - & 185 \\
GNP & 512 & 256 & 1535 & 1.0 & 20 & - & - & 173 \\
0.05VCF & 512 & 256 & 1535 & 0.2 & - & 0.9 & - & 177 \\
0.2VCF & 512 & 256 & 1535 & 0.5 & - & 3.4 & - & 170 \\
0.05RCF & 512 & 256 & 1535 & 0.3 & - & - & 0.9 & 205 \\
0.2RCF & 512 & 256 & 1535 & 0.6 & - & - & 3.7 & 177 \\
GNP-0.05VCF & 512 & 256 & 1535 & 1.1 & 20 & 0.9 & - & 200 \\
GNP-0.2VCF & 512 & 256 & 1535 & 1.9 & 20 & 3.4 & - & 177 \\
GNP-0.05RCF & 512 & 256 & 1535 & 1.8 & 20 & - & 0.9 & 193 \\
GNP-0.2RCF & 512 & 256 & 1535 & 2.4 & 20 & - & 3.7 & 177 \\
\hline
\end{tabular}




\subsection{Mechanical Tests of Mortars}

The mechanical properties of mortars were investigated by means of flexural and compressive tests. For flexure, a 3-point bending test was carried out on $40 \times 40 \times 160 \mathrm{~mm}$ specimens after 28 days of curing. For compression, the same specimens were tested after 28 days of curing. Mechanical tests were carried out on three specimens according to the UNI EN 1015-11:2007 standard.

\subsection{Electrical Tests of Mortars}

\subsubsection{Electrical Resistivity Measurements}

The electrical conductivity of mortars was investigated through electrical resistivity measurements after 28 days of curing both before and after drying them at $60^{\circ} \mathrm{C}$ until a constant mass was reached. This last condition was chosen in order to reduce the effect of moisture on electrical conduction [28]. Specimens used for electrical tests had $40 \times 40 \times 160 \mathrm{~mm}$ dimensions. Four stainless steel meshes, acting as electrodes, were placed inside the specimens with an immersion area of $30 \times 30 \mathrm{~mm}$ [29], after being previously degreased with acetone. The electrodes were placed at a distance of $40 \mathrm{~mm}$ from each other (Figure 2).

For measurements, a power supply (Protek DF1731SL5A) and a data acquisition device (Data Taker DT80) connected to a computer were used.

A potential difference was applied to the external electrodes in order to supply well-defined currents $I(t)$ (from $0.05-10 \mathrm{~mA}$ ) through the specimen. The voltage $U(t)$ between the two inner electrodes was detected by the data acquisition device, and the resistivity $\rho(t)$ was thus calculated through the first and the second Ohm's law, from which Equation (1) can be obtained:

$$
\rho(t)=\frac{U(t)}{I(t)} \frac{A}{1}
$$

where $\mathrm{U}(\mathrm{t})=$ voltage across the inner electrodes; $\mathrm{I}(\mathrm{t})=$ current measured between the outer electrodes; $\mathrm{A}=$ contact area between the electrodes and the material; and $1=$ spacing between the inner electrodes.

The test setup is given in Figure 2.

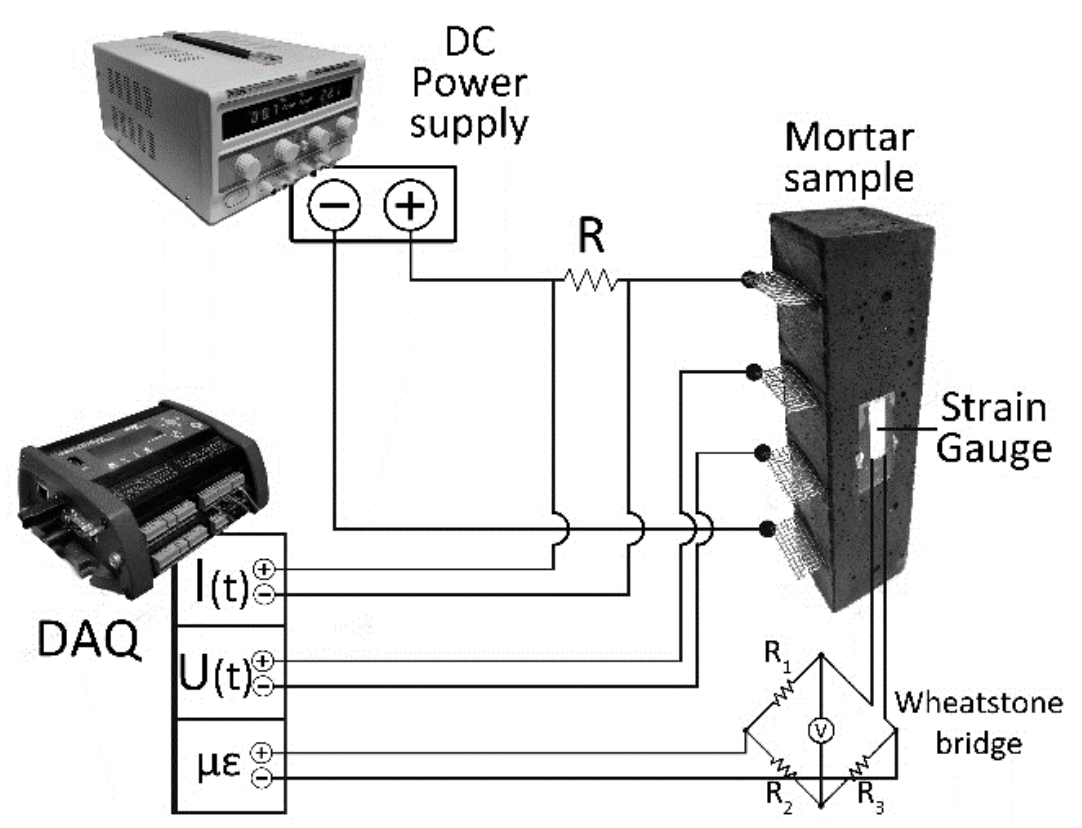

Figure 2. Setup for electrical measurements. 


\subsubsection{Piezoresistivity Measurements}

For piezoresistivity tests, the electrical resistivity testing of the materials subjected to compression load cycles was carried out through a continuous acquisition. Piezoresistivity measurements were carried out on specimens after 28 days of curing both before and after drying them at $60{ }^{\circ} \mathrm{C}$ until a constant mass was reached. In this way, the influence of humidity on the measured value can be minimized. For compression deformation measurements, a $15-\mathrm{mm} 120 \Omega$ strain gauge connected to the data acquisition device was applied in the middle of the specimen (Figure 2).

A potential difference of approximately $20 \mathrm{~V}$ was applied to the outer electrodes until stabilization of the resistivity value was reached. A Shimadzu AG-IC press applied a cyclic dynamic force of $250 \mathrm{~N} \cdot \mathrm{s}^{-1}$ to the sample, up to a maximum of $25 \mathrm{kN}(15.6 \mathrm{MPa})$ and a lower limit of $2 \mathrm{kN}$. For each test, 10 sequential cycles were applied, with a total time of $180 \mathrm{~s}$ each. The piezoresistive properties of the materials were evaluated through the calculation of the fractional change in resistivity (FCR) of the specimen according to Equation (2):

$$
\mathrm{FCR}=\frac{\rho(\mathrm{t})-\rho_{0}}{\rho_{0}}
$$

where $\rho(t)=$ maximum load resistivity of a sample; and $\rho_{0}=$ initial resistivity of the same sample.

The correlation between FCR and strain, defined as sensitivity, was evaluated through Equation (3):

$$
\text { sensitivity }=\frac{F C R}{\mu \varepsilon}
$$

where $\mu \varepsilon=$ axial deformation of the sample.

\section{Results and Discussion}

\subsection{Mechanical Properties of Mortars}

The mechanical properties of mortars are reported in Figure 3.

Concerning flexural strength $\left(\mathrm{R}_{\mathrm{f}}\right)$, REF mortar has an $\mathrm{R}_{\mathrm{f}}$ value equal to $6.9 \mathrm{MPa}$ (Figure 3a). The addition of commercial GNP at $4 \%$ by cement weight has not modified the flexural strength of the mortar, whose $R_{f}$ value is similar to that of REF and equal to 6.4 MPa. A similar result was found by Du and Pang [30], who found that the addition of GNP at 5\% by cement weight has an insignificant effect on flexural strength; however, at higher dosages, it leads to a decrease of the $R_{f}$ value. On the other hand, the addition of carbon fibers results in a slight increase of the mortars' flexural strength, especially for those manufactured with VCF. It is reported that the inclusion of fibers inside cement-based compounds is beneficial for increasing the resistance of the material under flexure and tension because of the bridging action of fibers [31]. The addition of GNP to mortars containing fibers decreases the flexural strength, and those manufactured with RCF show the worst mechanical results.

In case of compressive strength $\left(R_{c}\right)$, results show that REF mortar has an $R_{c}$ value of $31 \mathrm{MPa}$ (Figure $3 b$ ). The use of GNP slightly affects the compressive strength of the mortar, which shows an $R_{c}$ value of $29 \mathrm{MPa}$. As for GNP, the addition of carbon fibers does not modify the compressive strength of mortars, and only that manufactured with RCF at $0.05 \%$ in volume shows an $\mathrm{R}_{\mathrm{c}} 10 \%$ lower than that of the REF. On the contrary, when both GNP and fibers are used, the worsening of mechanical strength increases and becomes $12 \%$ lower for VCF and 19\% lower for RCF additions.

The penalization of the mechanical properties of mortars manufactured with GNP was already reported by some authors $[26,30]$ and is related to the hydrophobicity of graphene and its physical characteristics (specific surface area and bulk density) [32], as well as to the resulting difficulty in mixing during the preparation of specimens [33-35], which has contributed to an increased porosity of mortars [26]. The augmented porosity of mortars manufactured with GNP is visible in Figure 4, where the visual aspect of REF and GNP mortars is given. In this figure, it is possible to notice an 
increased number of voids in GNP mortar compared to the REF one, due to the difficult compaction during the casting activity.

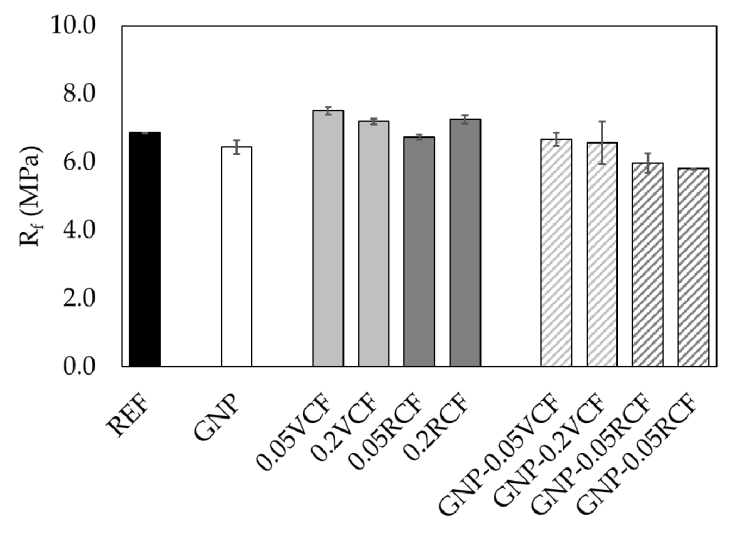

(a)

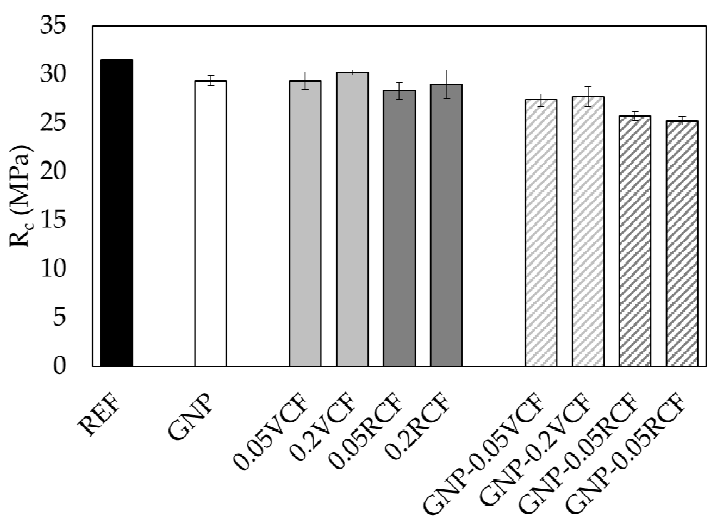

(b)

Figure 3. Flexural strength (a) and compressive strength (b) of mortars after 28 days of curing.

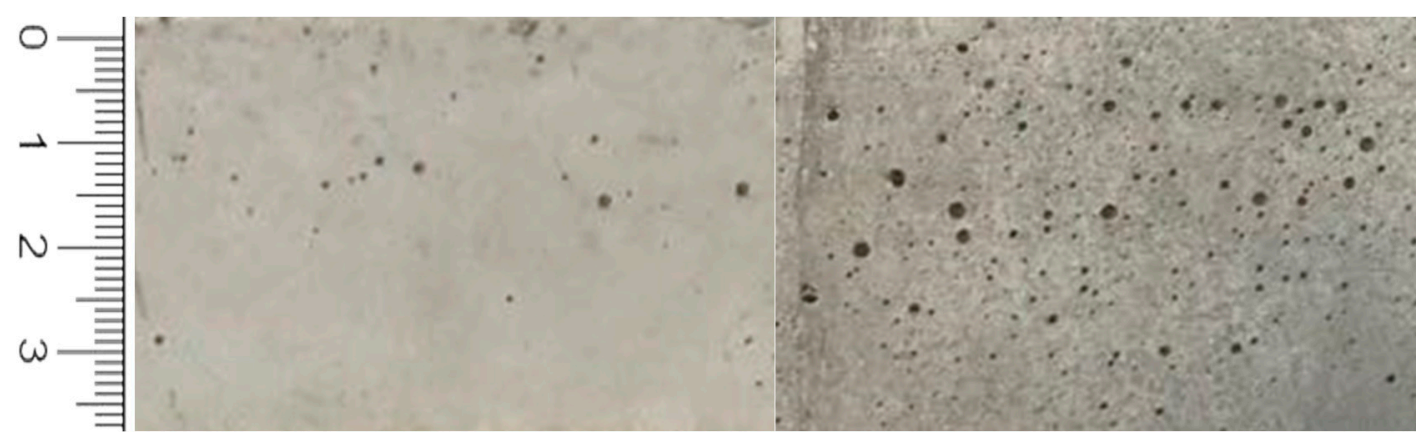

(a)

(b)

Figure 4. Visual aspect of (a) REF and (b) GNP mortars after 28 days of curing.

\subsection{Electrical Properties of Mortars}

\subsubsection{Electrical Resistivity}

The electrical resistivity of mortars is reported in Figure 5.

After the extraction from the climatic chamber (Figure 5a), the REF mortar shows an electrical resistivity $(\rho)$ of $80 \Omega \cdot \mathrm{m}$. The mortar manufactured with GNP shows a slightly lower value of $\rho$, equal to $73 \Omega \cdot \mathrm{m}$, which is only $8 \%$ lower than that of the reference. In the same way, mortars containing carbon fibers also confirm the $\rho$ value of the reference, and only that manufactured with VCF at $0.2 \mathrm{vol} . \%$ shows a decrease of electrical resistivity equal to $16 \%$ compared to that of REF mortar. On the contrary, the combined use of carbon fibers and carbon filler contributes to a further decrease of electrical resistivity. In fact, mortars manufactured with VCF and GNP show values $9 \%$ and $24 \%$ lower than REF when manufactured with fibers at 0.05 vol.\% and 0.2 vol.\%, respectively. When RCF and GNP are used together, the decrease in electrical resistivity reaches $19 \%$ and even $92 \%$ depending on whether 0.05 vol. $\%$ or 0.2 vol. $\%$ of fibers are added, respectively. However, the great decrease of the electrical resistivity of GNP-0.2RCF mortar is not related to the type and quantity of fibers used. On the contrary, it is due to the good dispersion of filler and recycled fibers. In fact, if the material is well distributed inside the matrix, it forms a continuous path for the current, contributing to increasing the electrical conductivity of the material [36].

Dried specimens show an increase in electrical resistivity up to two orders of magnitude (Figure $5 b$ ). This behavior is related to the water loss, which occurred after the drying process. 
In fact, the presence of water inside the material is beneficial for electrical conduction. The drying process has thus left the material filled with air instead of water, increasing its electrical resistivity.

REF mortar obtains a $\rho$ value of $2474 \Omega \cdot \mathrm{m}$. The use of GNP worsens the electrical conductivity of mortars, since the resistivity value becomes $61 \%$ higher than REF. This is due to the increased porosity of the mixture containing GNP (Figure 4). On the other hand, some mortars manufactured with carbon fibers show a different behavior: in fact, that manufactured with $0.05 \mathrm{vol} \%$ of RCF confirms the resistivity of REF, whereas $0.2 \mathrm{VCF}$ mortar shows a resistivity of $328 \Omega \cdot \mathrm{m}(87 \%$ less than REF). On the contrary, while the coupling of GNP and fibers increases the mortar $\rho$ value of $160 \%$, the GNP-0.2RCF mortar shows a resistivity of $5.3 \Omega \cdot \mathrm{m}$ (three orders of magnitude less than REF). Again, the use of virgin and recycled fibers gives contrasting results, and it is thus evident that it is not the typology of fibers that influences the electrical properties of the studied compounds.

Therefore, the high conductivity of the 0.2VCF and GNP-0.2RCF mixtures is not linked to the type of fibers used, but is probably related to the optimal distribution of the additions, which have formed an extremely effective conductive network within the material [37].

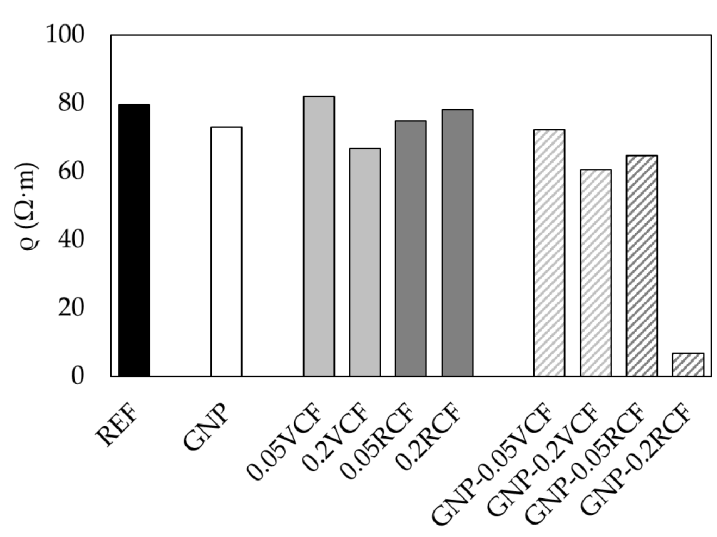

(a)

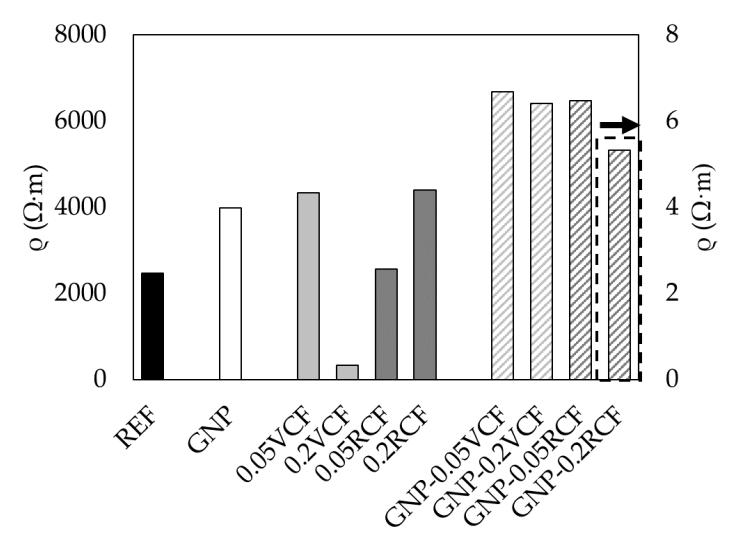

(b)

Figure 5. Electrical resistivity of 28-day cured mortars measured just after the extraction from the climatic chamber (a) and after drying (b).

\subsubsection{Piezoresistivity}

The piezoresistivity was evaluated in those specimens showing the lowest electrical resistivity, since a good electrical conduction is a prerequisite for piezoresistive behavior [38]. For these reasons, it was investigated in the 28-day cured GNP-0.2RCF mortar just after the extraction from the climatic chamber and in both 28-day cured $0.2 \mathrm{VCF}$ and GNP-0.2RCF mortars after the drying process (Figure $5 b$ ).

The result obtained from moist GNP-0.2RCF mortar shows that the specimen has no piezoresistive behavior (Figure 6). In fact, no variation for FCR has been detected during the cyclic variation of strain in time due to the cyclic application of compressive load. Even if the mortar is loaded with conductive material, the result obtained indicates that the conductive links built by the tunneling of GNP particles are not stable [26].

In the case of dried specimens, the results are completely different, because their high conductivity leads to a significant piezoresistive behavior (Figure 7). In fact, for both $0.2 \mathrm{VCF}$ and GNP-0.2RCF mortars in Figure 7a,c, respectively, it is possible to observe a sensible change of FCR under cyclic compressive loading. The change of electrical resistivity is thus sensitive to the applied stress. Moreover, these figures show a reversible trend of FCR, which decreases upon loading and increases upon unloading. This behavior establishes a straightforward correlation between deformation and resistivity [28], as shown in Figure $7 \mathrm{~b}$,d. In particular, $0.2 \mathrm{VCF}$ shows a very high sensitivity ( $613.5 \mathrm{MPa}^{-1}$ and a maximum value of $4.9 \%$ for FCR, Table 3 ), and the change in resistivity is constant and repeatable. However, the reading has some noise, as can be seen from the irregularity of the 
FCR-time curve (Figure 7a) since the conductivity is still governed by the tunneling effect [26]. On the contrary, GNP-0.2RCF shows a lower sensitivity (a maximum value of $2.2 \%$ for FCR with similar strain values, Table 3), but a very good regularity of its FCR-strain trend line without noise (Figure 7c), indicating that the tunneling effect is no longer disturbed by the applied load [26], probably because, in this case, the conductivity occurs also by contact between the additions. In fact, the high repeatability is due to the high conductivity of the material $\left(\rho_{0}=5.3 \Omega \cdot \mathrm{m}\right.$, Table 3$)$, which shows a piezoresistive behavior similar to a traditional strain gauge. A stable electrical conductivity and sensing sensitivity of cement-based composites manufactured with carbon fiber and graphite powder was reported also by Fan and coworkers [39]. Ou and Han observed that the coupling of carbon fibers and carbon black enhances the reproducibility and linearity of sensing performances. They attributed this effect to the combination of the two materials, which causes the movement of charges over long and short distances and enhances the contacting and tunneling conduction effect [40].

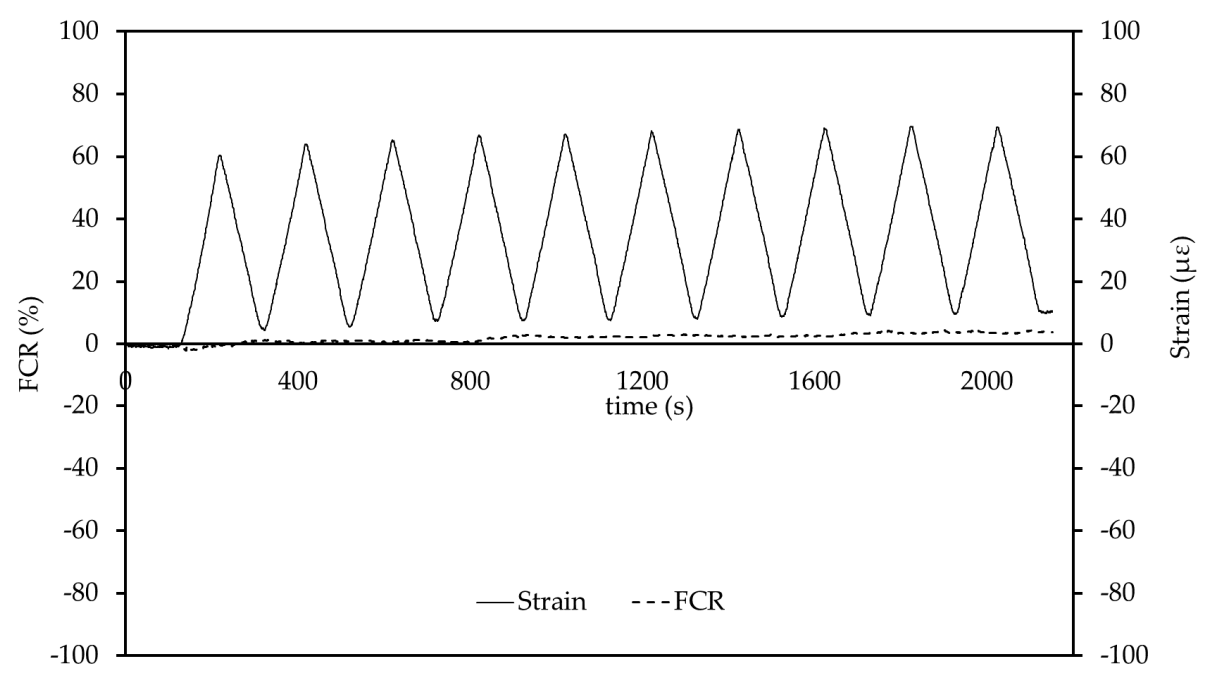

Figure 6. FCR and strain vs. time of the 28-day cured GNP-0.2RCF specimen under cyclic loading just after the extraction from the climatic chamber.

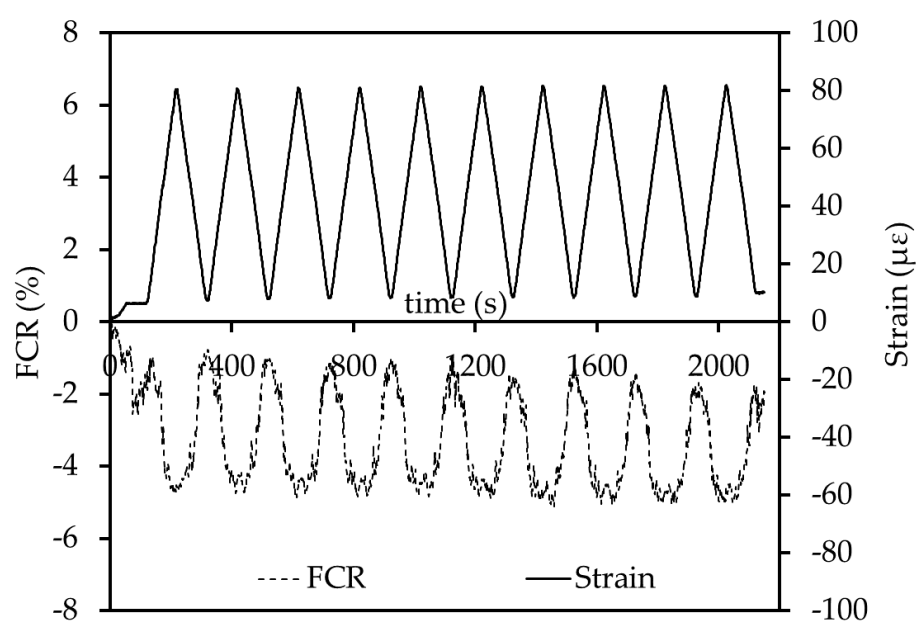

(a)

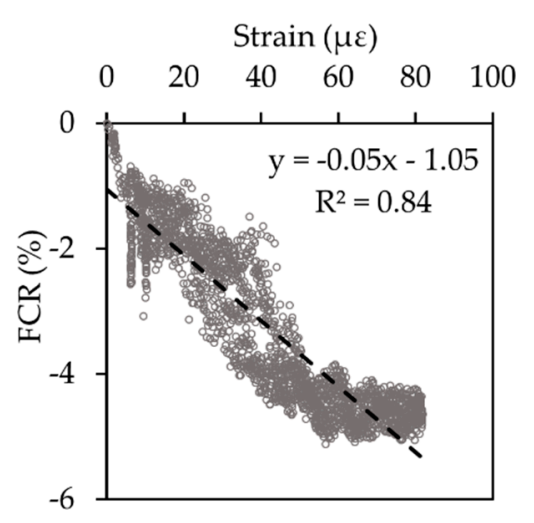

(b)

Figure 7. Cont. 


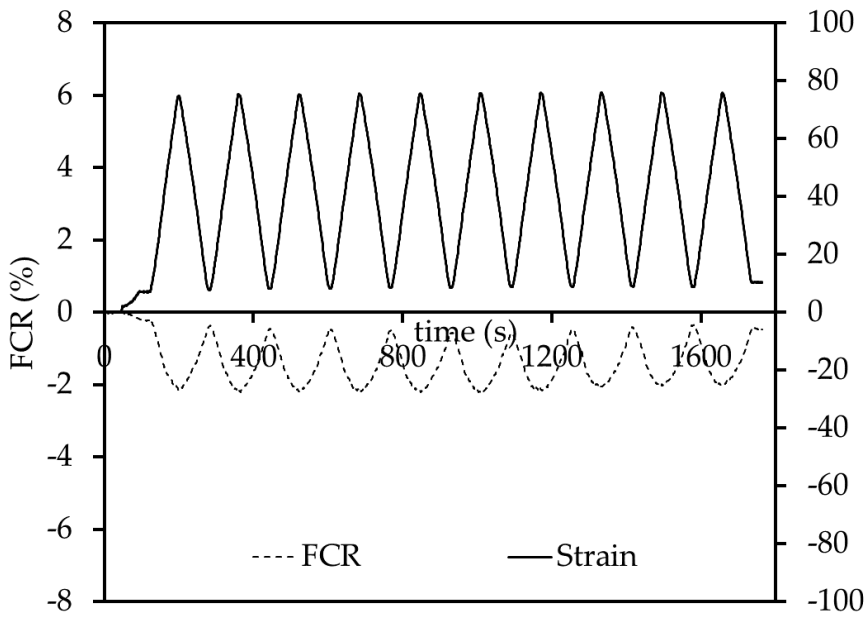

(c)

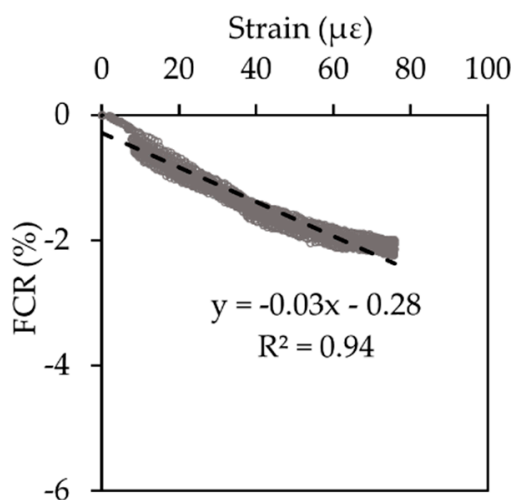

(d)

Figure 7. FCR and strain vs. time of the (a) dried 0.2VCF specimen and (b) dried GNP-0.2RCF specimen under cyclic loading. FCR-strain trend line of the (c) dried 0.2VCF specimen and (d) dried GNP-0.2RCF specimen.

Table 3. Electrical properties and piezoresistivity of $0.2 \mathrm{VCF}$ and GNP-0.2RCF mortars. FCR, fractional change in resistivity.

\begin{tabular}{ccc}
\hline Properties & 0.2VCF & GNP-0.2RCF \\
\hline$\rho_{0}(\Omega \cdot \mathrm{m})$ & 327.8 & 5.3 \\
Max. FCR $(\%)$ & 4.9 & 2.2 \\
Sensitivity $\left(\mathrm{MPa}^{-1}\right)$ & 613.5 & 295.4 \\
\hline
\end{tabular}

\section{Conclusions}

In this work, the electrical and mechanical properties of mortars manufactured with conductive carbon-based fillers and fibers have been investigated for the development of cement-based sensors for self-sensing systems. As a conductive filler, graphene nanoplatelets (GNP) were used. As conductive fibers, both virgin carbon fibers (VCF) and recycled carbon fibers (RCF) have been chosen.

The experimental results show the following:

- GNP leads to a decrease in mechanical strength and an increase in electrical resistivity due to the increased content of voids as a consequence of the difficult compaction of the mortar;

- In order to show piezoresistive behavior, after curing, specimens should be dried;

- VCF addition at 0.2 vol. $\%$ and the combined use of GNP and RCF at 0.2 vol. $\%$ entail a very high electrical conductivity and clear piezoresistive properties.

Author Contributions: A.M. and A.B. dealt with literature review and writing. A.B. prepared the specimens, carried out the tests and prepared the original draft. T.B organized the methodology and software preparation and reviewed the paper. A.M and A.B. analyzed the data. P.C. provided the materials, the resources and the equipment and coordinated the work. A.M. reviewed, wrote and edited the final paper. F.T. reviewed the paper and supervised the work.

Funding: This research received no external funding. The APC was funded by Francesca Tittarelli and Alessandra Mobili. Research Unit RISCO is funded by the Portuguese Foundation for Science and Technology (FCT) project FCT/UID/ECI/04450/2013.

Conflicts of Interest: The authors declare no conflict of interest. 


\section{References}

1. Tittarelli, F.; Giosuè, C.; Mobili, A.; Ruello, M.L. Influence of binders and aggregates on VOCs adsorption and moisture buffering activity of mortars for indoor applications. Cem. Concr. Compos. 2015, 57, 75-83. [CrossRef]

2. Giosuè, C.; Belli, A.; Mobili, A.; Citterio, B.; Biavasco, F.; Ruello, M.L.; Tittarelli, F. Improving the Impact of Commercial Paint on Indoor Air Quality by Using Highly Porous Fillers. Buildings 2017, 7, 110. [CrossRef]

3. Giosuè, C.; Mobili, A.; Toscano, G.; Ruello, M.L.; Tittarelli, F. Effect of Biomass Waste Materials as Unconventional Aggregates in Multifunctional Mortars for Indoor Application. Procedia Eng. 2016, 161, 655-659. [CrossRef]

4. Li, Z.; Ding, S.; Yu, X.; Han, B.; Ou, J. Multifunctional cementitious composites modified with nano titanium dioxide: A review. Compos. Part A Appl. Sci. Manuf. 2018, 111, 115-137. [CrossRef]

5. Giosuè, C.; Pierpaoli, M.; Mobili, A.; Ruello, M.L.; Tittarelli, F. Influence of Binders and Lightweight Aggregates on the Properties of Cementitious Mortars: From Traditional Requirements to Indoor Air Quality Improvement. Materials 2017, 10, 978. [CrossRef] [PubMed]

6. Giosuè, C.; Yu, Q.L.; Ruello, M.L.; Tittarelli, F.; Brouwers, H.J.H. Effect of pore structure on the performance of photocatalytic lightweight lime-based finishing mortar. Constr. Build. Mater. 2018, 171, 232-242. [CrossRef]

7. D'Alessandro, A.; Pisello, A.L.; Fabiani, C.; Ubertini, F.; Cabeza, L.F.; Cotana, F. Multifunctional smart concretes with novel phase change materials: Mechanical and thermo-energy investigation. Appl. Energy 2018, 212, 1448-1461. [CrossRef]

8. Coppola, L.; Coffetti, D.; Lorenzi, S. Cement-Based Renders Manufactured with Phase-Change Materials: Applications and Feasibility. Adv. Mater. Sci. Eng. 2016, 2016. [CrossRef]

9. Donnini, J.; Bellezze, T.; Corinaldesi, V. Mechanical, electrical and self-sensing properties of cementitious mortars containing short carbon fibers. J. Build. Eng. 2018, 20, 8-14. [CrossRef]

10. Chung, D.D.L. Carbon materials for structural self-sensing, electromagnetic shielding and thermal interfacing. Carbon N. Y. 2012, 50, 3342-3353. [CrossRef]

11. Ubertini, F.; Alessandro, A.D.; Materazzi, A.L.; Laflamme, S.; Downey, A. Novel nanocomposite clay brick for strain sensing in structural masonry. In Proceedings of the Environment and Electrical Engineering and 2017 IEEE Industrial and Commercial Power Systems Europe (EEEIC/I\&CPS Europe), Milan, Italy, 6-9 June 2017; pp. 1-4.

12. Chung, D.D.L. Electrically conductive cement-based materials. Adv. Cem. Res. 2004, 4, 167-176. [CrossRef]

13. Brownjohn, J.M. Structural health monitoring of civil infrastructure. Philos. Trans. R. Soc. Lond. A Math. Phys. Eng. Sci. 2007, 365, 589-622. [CrossRef] [PubMed]

14. Wen, S.; Chung, D.D.L. Piezoresistivity-based strain sensing in carbon fiber-reinforced cement. ACI Mater. J. 2007, 104, 171-179.

15. Rajabipour, F.; Weiss, J. Electrical conductivity of drying cement paste. Mater. Struct. 2007, 40, 1143-1160. [CrossRef]

16. Han, B.; Ding, S.; Yu, X. Intrinsic self-sensing concrete and structures: A review. Measurement 2015, 59, 110-128. [CrossRef]

17. Wen, S.; Chung, D.D.L. Partial replacement of carbon fiber by carbon black in multifunctional cement-matrix composites. Carbon N. Y. 2007, 45, 505-513. [CrossRef]

18. Chung, D.D.L. Carbon Fiber Composites; Butterworth-Heinemann: Newton, MA, USA, 1994; Volume 9.

19. Qiang, Z.; Gurkan, B.; Ma, J.; Liu, X.; Guo, Y.; Cakmak, M.; Cavicchi, K.A.; Vogt, B.D. Roll-to-roll fabrication of high surface area mesoporous carbon with process-tunable pore texture for optimization of adsorption capacity of bulky organic dyes. Microporous Mesoporous Mater. 2016, 227, 57-64. [CrossRef]

20. Deng, G.; Qiang, Z.; Lecorchick, W.; Cavicchi, K.A.; Vogt, B.D. Nanoporous nonwoven fibril-like morphology by cooperative self-assembly of poly(ethylene oxide)-block-poly(ethyl acrylate)-block-polystyrene and phenolic resin. Langmuir 2014, 30, 2530-2540. [CrossRef] [PubMed]

21. Chuah, S.; Pan, Z.; Sanjayan, J.G.; Wang, C.M.; Duan, W.H. Nano reinforced cement and concrete composites and new perspective from graphene oxide. Constr. Build. Mater. 2014, 73, 113-124. [CrossRef]

22. Singh, V.; Joung, D.; Zhai, L.; Das, S.; Khondaker, S.I.; Seal, S. Graphene based materials: Past, present and future. Prog. Mater. Sci. 2011, 56, 1178-1271. [CrossRef] 
23. Le, J.-L.; Du, H.; Pang, S.D. Use of 2D Graphene Nanoplatelets (GNP) in cement composites for structural health evaluation. Compos. Part B Eng. 2014, 67, 555-563. [CrossRef]

24. Gupta, A.; Sakthivel, T.; Seal, S. Recent development in 2D materials beyond graphene. Prog. Mater. Sci. 2015, 73, 44-126. [CrossRef]

25. Du, H.; Pang, S.D. Mechanical Response and Strain Sensing of Cement Composites Added with Graphene Nanoplatelet Under Tension. In Nanotechnology in Construction; Sobolev, K., Shah, V., Eds.; Springer: Cham, Switzerland, 2015; pp. 377-382.

26. Liu, Q.; Xu, Q.; Yu, Q.; Gao, R.; Tong, T. Experimental investigation on mechanical and piezoresistive properties of cementitious materials containing graphene and graphene oxide nanoplatelets. Constr. Build. Mater. 2016, 127, 565-576. [CrossRef]

27. Chen, P.-W.; Chung, D.D.L. Carbon fiber reinforced concrete as an intrinsically smart concrete for damage assessment during static and dynamic loading.pdf. ACI Mater. J. 1996, 93, 341-350.

28. Monteiro, A.O.; Cachim, P.B.; Costa, P.M.F.J. Self-sensing piezoresistive cement composite loaded with carbon black particles. Cem. Concr. Compos. 2017, 81, 59-65. [CrossRef]

29. Han, B.; Guan, X.; Ou, J. Electrode design, measuring method and data acquisition system of carbon fiber cement paste piezoresistive sensors. Sens. Actuators A Phys. 2007, 135, 360-369. [CrossRef]

30. Du, H.; Pang, S.D. Enhancement of barrier properties of cement mortar with graphene nanoplatelet. Cem. Concr. Res. 2015, 76, 10-19. [CrossRef]

31. Mastali, M.; Dalvand, A. The impact resistance and mechanical properties of self-compacting concrete reinforced with recycled CFRP pieces. Compos. Part B Eng. 2016, 92, 360-376. [CrossRef]

32. Shamsaei, E.; de Souza, F.B.; Yao, X.; Benhelal, E.; Akbari, A.; Duan, W. Graphene-based nanosheets for stronger and more durable concrete: A review. Constr. Build. Mater. 2018, 183, 642-660. [CrossRef]

33. Li, X.; Liu, Y.M.; Li, W.G.; Li, C.Y.; Sanjayan, J.G.; Duan, W.H.; Li, Z. Effects of graphene oxide agglomerates on workability, hydration, microstructure and compressive strength of cement paste. Constr. Build. Mater. 2017, 145, 402-410. [CrossRef]

34. Al-Dahawi, A.; Öztürk, O.; Emami, F.; Yildirim, G.; Şahmaran, M. Effect of mixing methods on the electrical properties of cementitious composites incorporating different carbon-based materials. Constr. Build. Mater. 2016, 104, 160-168. [CrossRef]

35. Mobili, A.; Belli, A.; Giosuè, C.; Pierpaoli, M.; Bastianelli, L.; Mazzoli, A.; Ruello, M.L.; Bellezze, T.; Tittarelli, F. Enhancing the mechanical, durability, depolluting and electrical properties of multifunctional lime mortars by commercial or waste carbonaceous fillers addition. Cem. Concr. Compos. 2017. submit for publication.

36. Chung, D.D.L. Dispersion of Short Fibers in Cement. J. Mater. Civ. Eng. 2005, 17, 379-383. [CrossRef]

37. Han, B.; Yu, X.; Ou, J. Multifunctional and smart nanotube reinforced cement-based materials. In Nanotechnology in Civil Infrastructure; Gopalakrishnan, K., Birgisson, B., Taylor, P., Attoh-Okine, N.O., Eds.; Springer: Berlin/Heidelberg, Germany, 2011; pp. 1-47.

38. Chung, D.D.L. Piezoresistive Cement-Based Materials for Strain Sensing. J. Intell. Mater. Syst. Struct. 2002, 13, 599-609. [CrossRef]

39. Fan, X.; Fang, D.; Sun, M.; Li, Z. Piezoresistivity of carbon fiber graphite cement-based composites with CCCW. J. Wuhan Univ. Technol. Mater. Sci. Ed. 2011, 26, 339-343. [CrossRef]

40. Ou, J.; Han, B. Piezoresistive cement-based strain sensors and self-sensing concrete components. J. Intell. Mater. Syst. Struct. 2009, 20, 329-336. [CrossRef]

(C) 2018 by the authors. Licensee MDPI, Basel, Switzerland. This article is an open access article distributed under the terms and conditions of the Creative Commons Attribution (CC BY) license (http://creativecommons.org/licenses/by/4.0/). 